\title{
Helen Salisbury: No time for decision making
}

\author{
Helen Salisbury GP \\ Oxford
}

The world's been turned upside down in the past six weeks, and many people's familiar routines of work, school, family, and friends are gone. Although GPs are not immune, the disruption we face is comparatively mild. We've changed our way of working, consulting mostly by phone or video link, but most of us are still going into the surgery and meeting colleagues, albeit at a two metre distance.

Many GPs are also staffing covid clinics in the community, and we're getting used to donning and doffing masks and aprons. In our practice we had a phase of reorganisation, followed by a strange lull when almost all patient contacts were about coronavirus, and now a flood of patients who realise that their symptoms won't wait until this is over. It feels good to get on with ordinary medicine again, picking up threads with patients who stayed away because they feared that we were too busy.

There are several things we're not missing, and we're breathing a collective sigh of relief as the regulatory burden on general practice is (temporarily) lifted. The Quality and Outcomes Framework, the Care Quality Commission, and annual appraisals are all on hold, and many of us feel able to concentrate for the first time in years on providing the best care possible to our patients, without constantly worrying about the hoops we need to jump through to keep practices afloat. We're prioritising work according to our professional, clinical judgment.

Alas, this relief may be short lived. At the end of last year a new part of the GP contract was proposed-the primary care network direct enhanced service-which didn't go down well with the profession. ${ }^{1}$ A revised version has been presented that's slightly less bad, ${ }^{2}$ but a special conference of local medical committees on 11 March voted against accepting it. ${ }^{34}$ Some fear that this is the route by which practices will lose their autonomy, with activity judged at network rather than practice level. Initially this applies to cancer care reviews and extended hours provision - but the direction of travel, towards ever closer integration, is what worries many GPs. There are also major concerns that the extra funding may not compensate for the work involved, leaving some practices worse off financially, particularly those looking after nursing homes.

Each practice must say yes or no next month, but many of us would like to hit pause. Now is not the moment to be taking decisions that will have major implications for the future of our practices and the way we work. In the middle of this pandemic, few of us have had the time or headspace to consider the 87 page contract in detail. We need to meet, discuss, and take decisions together: there's much uncertainty about what will happen if a few of us say no or if many opt out.

Perhaps NHS England is hoping that we won't have the energy to scrutinise what's on offer and will sign up anyway, for fear of missing out on substantial funding. I have no illusions about the current reprieve from micromanagement lasting; indeed, it may get worse. One of the likely outcomes of this primary care network direct enhanced service is yet more box ticking and hoop jumping - all of it of marginal benefit to our patients.

\section{Competing interests: See www.bmj.com/about-bmj/freelance-contributors.}

Provenance and peer review: Commissioned; not externally peer reviewed.

1 lacobucci G. New primary care network contract won't work, GPs warn. BMJ 2020;368:m39. 10.1136/bmj.m39 31911450

2 NHS England and NHS Improvement. Network contract directed enhanced service: contract specification 2020/21-PCN requirements and entitlements. Mar 2020. https:// www.england.nhs.uk/wp-content/uploads/2020/03/network-contract-des-specificationpcn-requirements-entitlements-2020-21.pdf.

3 Berkshire, Buckinghamshire \& Oxfordshire LMCs. LMC summary briefing on the PCN DES. 20 Apr 2020. https://www.bbolmc.co.uk/importantlmcsummarybriefingonthepcndes. 4 Pearce C. LMC leaders vote to reject the network DES. Pulse 2020 Mar 11. http://www. pulsetoday.co.uk/news/gp-contract-2020/21/lmc-leaders-vote-to-reject-the-network-des/ 20040327.article.

Published by the BMJ Publishing Group Limited. For permission to use (where not already granted under a licence) please go to http://group.bmj.com/group/rights-licensing/ permissions 